\title{
Occurrence and harmfulness of Pestalotiopsis funerea to ornamental coniferous plants
}

\author{
Występowanie i szkodliwość Pestalotiopsis funerea \\ dla iglastych roślin ozdobnych
}

Leszek B. Orlikowski, Magdalena Ptaszek, Wojciech Warabieda

\section{Summary}

Surveying of coniferous plants in the years 2010-2011 showed the occurrence of necrotic lesions on shoot tips on about 0.5 to $9 \%$ of Lawson cypress, juniper, microbiota and thuja. The disease dominated on thuja shoots. Isolates of Pestalotiopsis funerea from juniper and thuja colonised stem parts of different species and cultivars of both plants. Significant differences in susceptibility of juniper and thuja to $P$. funerea were noticed. Isolates of the species from ericaceous plants caused shoot necrosis of heather and 6 species of coniferous plants. The disease spread, about 2 times faster on heather plants than on juniper and thuja. The trial with $P$. funerea growth in relation to temperature showed that $20-25^{\circ} \mathrm{C}$ is an optimal temperature for pathogen development.

Key words: coniferous plants; Pestalotiopsis funerea; isolates; occurrence; colonization

\section{Streszczenie}

Ocena występowania i zagrożenia roślin iglastych przez Pestalotiopsis funerea w latach 2010-2011 wykazała występowanie nekrotycznych plam na wierzchołkach pędów od 0,5 do 9\% w uprawach: cyprysika Lawsona, jałowca, mikrobioty syberyjskiej i żywotnika zachodniego. Choroba dominowała na pędach żywotnika. Izolaty $P$. funerea z jałowca i żywotnika kolonizowały fragmenty pędów różnych gatunków i odmian obu badanych roślin. Stwierdzono istotne różnice $w$ reakcji roślin na badane izolaty. Izolaty P. funerea z roślin wrzosowatych powodowały nekrozę wierzchołkowych pędów wrzosów i 6 gatunków roślin iglastych. Zgnilizna rozszerzała się 2-krotnie szybciej na wrzosach aniżeli na jałowcu i żywotniku. Doświadczenie nad wpływem temperatury na rozwój izolatów $P$. funerea wykazało najszybszy wzrost patogena w $20-25^{\circ} \mathrm{C}$.

Słowa kluczowe: rośliny iglaste; Pestalotiopsis funerea; izolaty; występowanie; kolonizacja

Instytut Ogrodnictwa

Konstytucji 3 Maja 1/3, 96-100 Skierniewice

leszek.orlikowski@inhort.pl 


\section{Wstęp / Introduction}

W 1839 roku de Notaris stwierdził po raz pierwszy na owocach winorośli we Włoszech występowanie nowego gatunku grzyba, którego zadedykował winiarzowi F. Pestalotzza (Guba 1961). Od jego nazwiska pochodzi łacińska nazwa rodzajowa Pestalotia. Cztery lata później, wśród znanych już gatunków opisany został $P$. funerea Desm. Gatunek ten stwierdzono m.in. na Abies lanceolata, Chamaecyparis lawsoniana, Ch. pisifera, Cryptomeria japonica, Cupressus flavescens, Juniperus sp., Pinus taeda, Podocarpus latifolia, Thuja occidentalis i T. orientalis, przy czym zasiedlał on korzenie starszych roślin oraz siewek i sadzonek oraz powodował gumozę cyprysika (Guba 1961). Zainteresowanie tym gatunkiem wzrosło pod koniec 20. i na początku 21. wieku, gdy w wielu krajach stwierdzono jego szkodliwość dla różnych gatunków roślin. W Izraelu omawiany gatunek zidentyfikowano na cyprysie (Madar i wsp. 1991), a w Turcji na żywotniku zachodnim (Ozan i wsp. 2012). W Polsce Grabowski i Obere (2009) wymieniają $P$. funerea wśród innych gatunków grzybów jako przyczynę nekrotycznych plam na pędach żywotnika zachodniego. W krajowych szkółkach roślin ozdobnych dotychczas dużo uwagi poświęcano patogenom glebowym, w tym głównie Phytophthora i Cylindrocladium, z uwagi na często masowe wypadanie nasadzeń z powodu zgnilizny podstawy pędu i korzeni (Orlikowski i Jarecka 2005; Orlikowski i wsp. 2012). Jednak już w pierwszych latach 21. wieku, głównie na roślinach iglastych, pojawiały się początkowo rzadko lub sporadycznie, objawy zamierania wierzchołkowych części pędów (Orlikowski, niepublikowane).

Celem badań było określenie zagrożenia ozdobnych roślin iglastych przez $P$. funerea, ocena szkodliwości izolatów tego gatunku $\mathrm{z}$ różnych żywicieli, a także wpływ temperatury na rozwój izolatów tego patogena.

\section{Materiały i metody / Materials and methods}

Lokalizacja badań. Badania przeprowadzono w 3 pojemnikowych szkółkach roślin ozdobnych usytuowanych w województwie lubelskim oraz w laboratorium Pracowni Fitopatologii Roślin Ozdobnych Instytutu Ogrodnictwa w Skierniewicach.

Material badawczy. W latach 2010 i 2011, w okresie wiosny (kwiecień-maj) przeprowadzono szczegółowe obserwacje występowania nekrotycznej plamistości lub zamierania wierzchołków pędów w szkółkach. Z uwagi na najczęstsze występowanie choroby na roślinach w jednej szkółce, ocenę porażenia przeprowadzono również w czerwcu i lipcu w tym obiekcie. Przedmiotem zainteresowania były: cyprysik Lawsona, jałowiec, mikrobiota syberyjska i żywotnik zachodni odmiana Smaragd. Idąc po 2 przekątnych kontenerowni oceniano liczbę roślin $\mathrm{z}$ objawami plamistości, występującej najczęściej na wierzchołkowej części pędów lub ich zamierania. Oceną objęto 400 roślin z każdego gatunku i powtórzono ją w następnym roku. Dla potwierdzenia czy przyczyną choroby jest $P$. funerea, $\mathrm{z}$ badanych gatunków roślin pobierano chore pędy i przewożono je do laboratorium Pracowni Chorób Roślin
Ozdobnych Instytutu Ogrodnictwa w celu wykonania analizy mikologicznej, stosując metodę opisaną przez Orlikowskiego i Szkutę (2002). Fragmenty pędów z objawami plamistości odkażano powierzchniowo nad płomieniem palnika i $5 \mathrm{~mm}$ skrawki wykładano na pożywkę PDA (Potato Dextrose Agar). W ciagu 24-48 godzin inkubacji w temperaturze $25^{\circ} \mathrm{C}$, wyrastające wokół wyłożonych skrawków kolonie patogenów przeszczepiano na PDA i po wstępnej segregacji izolaty reprezentacyjne oznaczano do gatunku na podstawie ich cech morfologicznych w oparciu o dostępne klucze.

Przygotowanie kolekcji izolatów $P$. funerea $\mathrm{z}$ różnych roślin żywicielskich. W ciagu 3 lat, obok roślin iglastych, izolaty $P$. funerea wyizolowano $\mathrm{z}$ większości gatunków roślin wrzosowatych oraz wody stosując metodę opisaną przez Orlikowskiego i Szkutę (2002). Kultury wykorzystano do oceny szkodliwości patogena dla: wrzosów, cyprysika Lawsona, jałowca, świerku, sosny, żywotnika zachodniego i cisa.

Kolonizacja wybranych gatunków roślin przez $P$. funerea. Izolaty grzyba wyizolowane z Juniperus media, Thuja occidentalis oraz z roślin wrzosowatych: Calluna vulgaris, Daboecia cantabrica, Erica carnea, Gaultheria procumbens, Leucothoe fontanesiana, Rhodoodendron sp. i dodatkowo ze stawu w szkółce wody (izolat PD) posłużyły do inokulacji wierzchołkowych części pędów roślin. Ich fragmenty, pobrane $\mathrm{z}$ różnych gatunków i odmian jałowca, żywotnika, wrzosu, cyprysika Lawsona, świerka, sosny i cisu umieszczano w kuwetach fotograficznych wyścielonych dwiema warstwami wilgotnej i sterylnej bibuły filtracyjnej, przykrytej cienką nylonową siatką. Następnie na ich wierzchołki nanoszono krążki grzybni o średnicy $5 \mathrm{~mm}$, pobrane $\mathrm{z}$ brzegów 7-dniowych kolonii izolatów rosnących na pożywce (PDA) w $25^{\circ} \mathrm{C}$ w ciemności. Kuwety okrywano szczelnie folią i inkubowano je 6 dni w temperaturze $22-24^{\circ} \mathrm{C}$. Po tym czasie mierzono długość nekrozy.

Doświadczenia założono w układzie kompletnie losowym w 4 powtórzeniach po 10 pędów. Powtórzono je 2-krotnie w odstępie 2 tygodni. Wyniki z przeprowadzonych doświadczeń opracowano statystycznie metodą analizy wariancji. Istotność różnic pomiędzy średnimi $(\mathrm{p}=0,05)$ oceniono testem Duncana.

Wpływ temperatury na rozwój $P$. funerea na pożywce PDA. Do testu wybrano izolaty grzyba z: różanecznika, dabecji, wrzosu i kiścienia. Krążki pożywki o średnicy $5 \mathrm{~mm}$ pobrane $\mathrm{z}$ brzegów 7-dniowych kultur umieszczano w centralnej części szalek Petriego z pożywką PDA. Na spodniej stronie szalki wykreślano dwie prostopadłe linie krzyżujące się w centrum inokulum pod kątem prostym. Szalki inkubowano przez 24 godziny w temperaturze $20^{\circ} \mathrm{C}$ w celu zainicjowania wzrostu. Wzrost ten traktowano jako okres preinkubacji i nie brano go pod uwagę przy obliczaniu tempa rozwoju grzyba. Następnie szalki umieszczano w termostatach, w temperaturze $5-35^{\circ} \mathrm{C}$, $\mathrm{w}$ odstępach co $5^{\circ} \mathrm{C}$. Po 4 dniach inkubacji mierzono średnice kolonii wzdłuż dwóch prostopadle przecinających się linii (Hall 1993). Doświadczenie założono w 4 powtórzeniach po 1 szalce Petriego i powtórzono je 2-krotnie. 


\section{Wyniki i dyskusja / Results and discussion}

Przeprowadzona ocena polowa występowania $P$. funerea na 4 gatunkach najczęściej uprawianych roślin iglastych wykazała, że badany grzyb występował we wszystkich szkółkach w okresie 2-letnich badań, ale najwięcej zasiedlonych (odpowiednio 7,5 i 9\%) było żywotników (rys. 1). Na 3 pozostałych gatunkach stwierdzono do 2,5\% zainfekowanych roślin (rys. 1). W drugim roku obserwacje wykazały rosnącą liczbę zasiedlonych roślin przez $P$. funerea (rys. 1).

Uzyskane dane wskazują na zróżnicowaną reakcję gatunków i odmian roślin na $P$. funerea (tab. 1). Na jałowcach najwolniejszy rozwój nekrozy stwierdzono na odmianach: J. communis, 3 odmianach J. horizontalis, $J$. media Hetzii, J. procumbens Nana i J. virginiana Grey Owl (tab. 1). W drugiej grupie znalazły się 2 odmiany $J$. horizontalis oraz $J$. squamata Mayeri. Najszybciej, bo około 3-4-krotnie w porównaniu do pierwszej grupy, kolonizowane były odmiany: J. media Pfitzeriana Aurea i Pfitzeriana Compacta (tab. 1).

Analiza kolonizacji wierzchołków pędów żywotnika (tab. 2) wskazuje, że zgnilizna nie rozwijała się na odmianach Mr Bowling Ball i Weimar oraz bardzo wolno na większości innych (średnio około $3 \mathrm{~mm}$ w ciągu $6 \mathrm{dni}$ ). W grupie tej znajduje się również odmiana Smaragd, jedna z najczęściej uprawianych w szkółkach. Około 2-krotnie szybszą kolonizację tkanek stwierdzono na odmianach: Aurea Nana, Spiralis, Teddy, Vogue Beauty, a najszybszą na odmianie Golden Tuffet (tab. 2).

W badaniach nad współzależnością pomiędzy źródłem izolatów $P$. funerea a kolonizacją pędów 7 gatunków roślin stwierdzono rozwój nekrozy na wszystkich testowanych pędach roślin iglastych i wrzosowatych (tab. 3). Obserwowano jednak istotne różnice w długości nekrozy w zależności od użytego izolatu. Kultury z G. procumbens i L. fontanesiana powodowały najszybszy rozwój nekrozy na pędach testowanych roślin. Niezależnie od izolatu użytego do inokulacji pędów, nekroza rozwijała się bardzo szybko na świerku i sośnie, a najwolniej na pędach cisa (tab. 3). Izolat ze stawu, do którego spływa nadmiar wody ze szkółki, powodował najszybszy rozwój nekrozy na świerku, a najwolniejszy na sośnie, żywotniku i cisie (tab. 3).

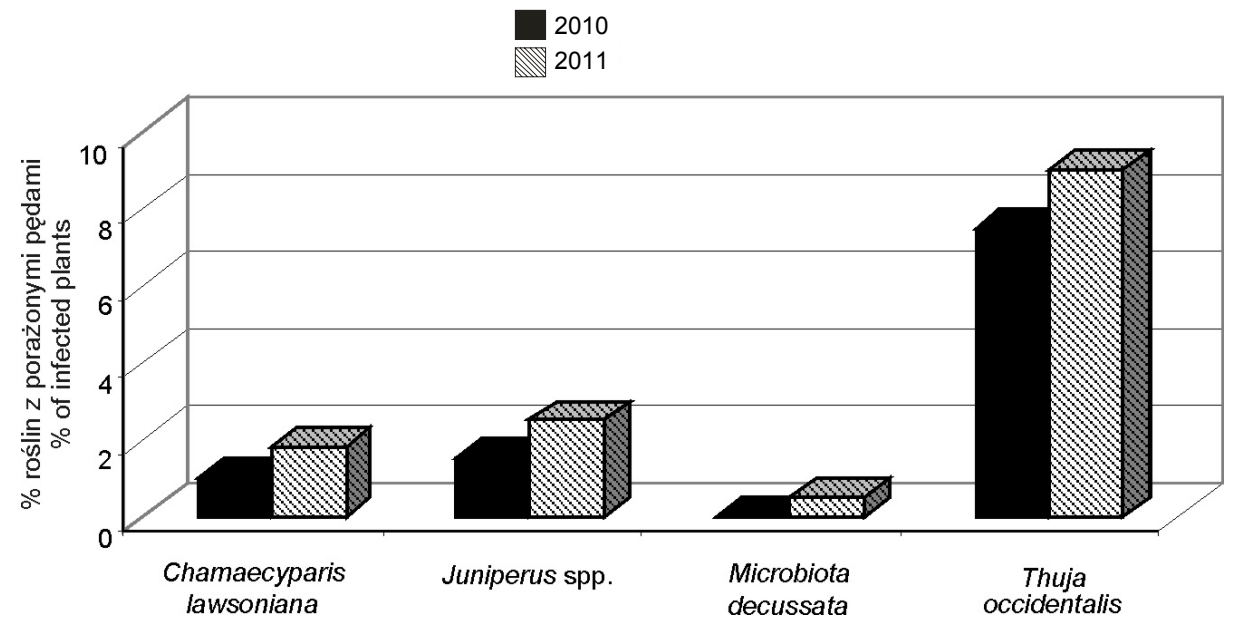

Rys. 1. Zagrożenie roślin iglastych w szkółkach pojemnikowych przez $P$. funerea

Fig. 1. Threat of coniferous plants in container ornamental nurseries by $P$. funerea

Tabela 1. Kolonizacja pędów jałowca (Juniperus spp.) przez P. funerea po 6 dniach inkubacji

Table 1. Colonisation of Juniperus spp. stem parts by P. funerea 6 days after inoculation

\begin{tabular}{|c|c|c|}
\hline $\begin{array}{l}\text { Grupy } \\
\text { Groups }\end{array}$ & $\begin{array}{l}\text { Gatunki i odmiany } \\
\text { Species and cultivars }\end{array}$ & $\begin{array}{l}\text { Długość nekrozy }[\mathrm{mm}] \\
\text { Length of necrosis }[\mathrm{mm}]\end{array}$ \\
\hline $\mathrm{I}$. & $\begin{array}{l}\text { J. communis Green Carpet, Repanda } \\
\text { J. horizontalis Glauca, Prince of Wales, Wiltonii } \\
\text { J. media Hetzii } \\
\text { J. procumbens Nana } \\
\text { J. squamata Blue Carpet } \\
\text { J. virginiana Grey Owl }\end{array}$ & 2,7 a do - to 4,9 a-d \\
\hline II. & $\begin{array}{l}\text { J. horizontalis Blue Chip, Golden Carpet } \\
\text { J. squamata Meyeri }\end{array}$ & $5,5 \mathrm{~b}-\mathrm{d}$ do - to $7,0 \mathrm{~d}$ \\
\hline III. & J. conferta Allgold, J. media Old Gold, Pfitzeriana Glauca & 9,1 e do - to 10,5 e \\
\hline IV. & J. media Pfitzeriana Aurea, Pfitzeriana Compacta & $12,0 \mathrm{fdo}-$ to $15,5 \mathrm{~g}$ \\
\hline
\end{tabular}

Średnie w kolumnach, oznaczone tę samą literą, nie różnią się istotnie (5\%) według testu Duncana

Means in columns, followed by the same letter, do not differ according to Duncan's multiple range test 
Tabela 2. Kolonizacja odmian żywotnika zachodniego przez $P$. funerea po 6 dniach inkubacji

Table 2. Colonisation of Thuja occidentalis cultivars by $P$. funerea 6 days after inoculation

\begin{tabular}{|c|c|c|}
\hline $\begin{array}{l}\text { Grupy } \\
\text { Groups }\end{array}$ & $\begin{array}{l}\text { Odmiany } \\
\text { Cultivars }\end{array}$ & $\begin{array}{l}\text { Długość nekrozy } \\
\text { Length of necrosis } \\
{[\mathrm{mm}]}\end{array}$ \\
\hline I. & Mr Bowling Ball, Weimar & 0 \\
\hline II. & $\begin{array}{l}\text { Aurescens, Danica, Danica Aurea, Degroot's Spire, Golden Globe, } \\
\text { Golden Tuffet, Hübner, Yellow Ribbon, Konfetti, Little Gem, Little } \\
\text { Giant } \\
\text { Little Champion, Mirjam, Smaragd, Smaragd White }\end{array}$ & $2,1 \mathrm{~b}$ do - to $3,8 \mathrm{c}$ \\
\hline III. & Aurea Nana, Spiralis, Teddy, Vogue Beauty & $5,6 \mathrm{~d}$ do - to $7,4 \mathrm{e}$ \\
\hline IV. & Golden Tuffet & $13,4 \mathrm{f}$ \\
\hline
\end{tabular}

Średnie w kolumnach, oznaczone tę samą literą, nie różnią się istotnie (5\%) według testu Duncana

Means in columns, followed by the same letter, do not differ according to Duncan's multiple range test

Tabela 3. Współzależność pomiędzy źródłem P. funerea, testowanymi roślinami a kolonizacją pędów; długość nekrozy [mm] po 6 dniach od inokulacji

Table 3. Relationship between $P$. funerea source and colonisation of stem parts of plants; length of necrosis [mm] 6 days after inoculation

\begin{tabular}{l|c|c|c|c|c|c|c}
\hline \multirow{2}{*}{$\begin{array}{c}\text { Źródło izolatów } \\
\text { Source of isolates }\end{array}$} & $\begin{array}{c}\text { Calluna } \\
\text { vulgaris }\end{array}$ & $\begin{array}{c}\text { Chamaecyparis } \\
\text { lawsoniana }\end{array}$ & $\begin{array}{c}\text { Juniperus } \\
\text { media }\end{array}$ & $\begin{array}{c}\text { Picea } \\
\text { excelsa }\end{array}$ & $\begin{array}{c}\text { Pinus } \\
\text { sylvestris }\end{array}$ & $\begin{array}{c}\text { Thuja } \\
\text { occidentalis } \\
\text { Smaragd }\end{array}$ & $\begin{array}{c}\text { Taxus } \\
\text { baccata }\end{array}$ \\
\cline { 2 - 9 } Calluna vulgaris & $18,4 \mathrm{l}-\mathrm{n}$ & $8,0 \mathrm{~d}-\mathrm{g}$ & $9,6 \mathrm{e}-\mathrm{h}$ & $15,4 \mathrm{j}-1$ & $27,5 \mathrm{p}-\mathrm{r}$ & $8,5 \mathrm{e}-\mathrm{g}$ & $3,4 \mathrm{a}$ \\
\hline Daboecia contabrica & $8,1 \mathrm{~d}-\mathrm{g}$ & $10,2 \mathrm{f}-\mathrm{i}$ & $8,0 \mathrm{~d}-\mathrm{g}$ & $18,9 \mathrm{mn}$ & $21,6 \mathrm{n}-\mathrm{p}$ & $6,1 \mathrm{a}-\mathrm{e}$ & $7,0 \mathrm{~b}-\mathrm{f}$ \\
\hline Erica carnea & $12,9 \mathrm{~h}-\mathrm{j}$ & $8,7 \mathrm{e}-\mathrm{g}$ & $11,1 \mathrm{~g}-\mathrm{i}$ & $19,0 \mathrm{mno}$ & $32,2 \mathrm{tu}$ & $6,8 \mathrm{a}-\mathrm{f}$ & $4,2 \mathrm{ab}$ \\
\hline Gaultheria procumbens & $36,0 \mathrm{v}$ & $24,7 \mathrm{pg}$ & $15,9 \mathrm{j}-\mathrm{m}$ & $21,0 \mathrm{no}$ & $36,0 \mathrm{v}$ & $22,3 \mathrm{op}$ & $10,1 \mathrm{f}-\mathrm{i}$ \\
\hline Leucothoe fontanesiana & $34,5 \mathrm{uv}$ & $30,7 \mathrm{st}$ & $16,3 \mathrm{k}-\mathrm{m}$ & $23,0 \mathrm{op}$ & $28,0 \mathrm{rs}$ & $27,2 \mathrm{qr}$ & $15,0 \mathrm{j}-\mathrm{k}$ \\
\hline Rhododendron sp. & $10,6 \mathrm{~g}-\mathrm{i}$ & $7,0 \mathrm{~b}-\mathrm{f}$ & $8,3 \mathrm{~d}-\mathrm{g}$ & $18,8 \mathrm{mn}$ & $23,5 \mathrm{op}$ & $4,8 \mathrm{a}-\mathrm{d}$ & $6,4 \mathrm{a}-\mathrm{e}$ \\
\hline $\begin{array}{l}\text { Staw PD } \\
\text { Water pond PD }\end{array}$ & $10,6 \mathrm{~g}-\mathrm{i}$ & $7,7 \mathrm{c}-\mathrm{g}$ & $9,2 \mathrm{e}-\mathrm{g}$ & $13,3 \mathrm{i}-\mathrm{k}$ & $4,4 \mathrm{a}-\mathrm{c}$ & $6,5 \mathrm{a}-\mathrm{e}$ & $4,0 \mathrm{ab}$ \\
\hline
\end{tabular}

Średnie w kolumnach, oznaczone tą samą literą, nie różnią się istotnie (5\%) według testu Duncana

Means in columns, followed by the same letter, do not differ according to Duncan's multiple range test

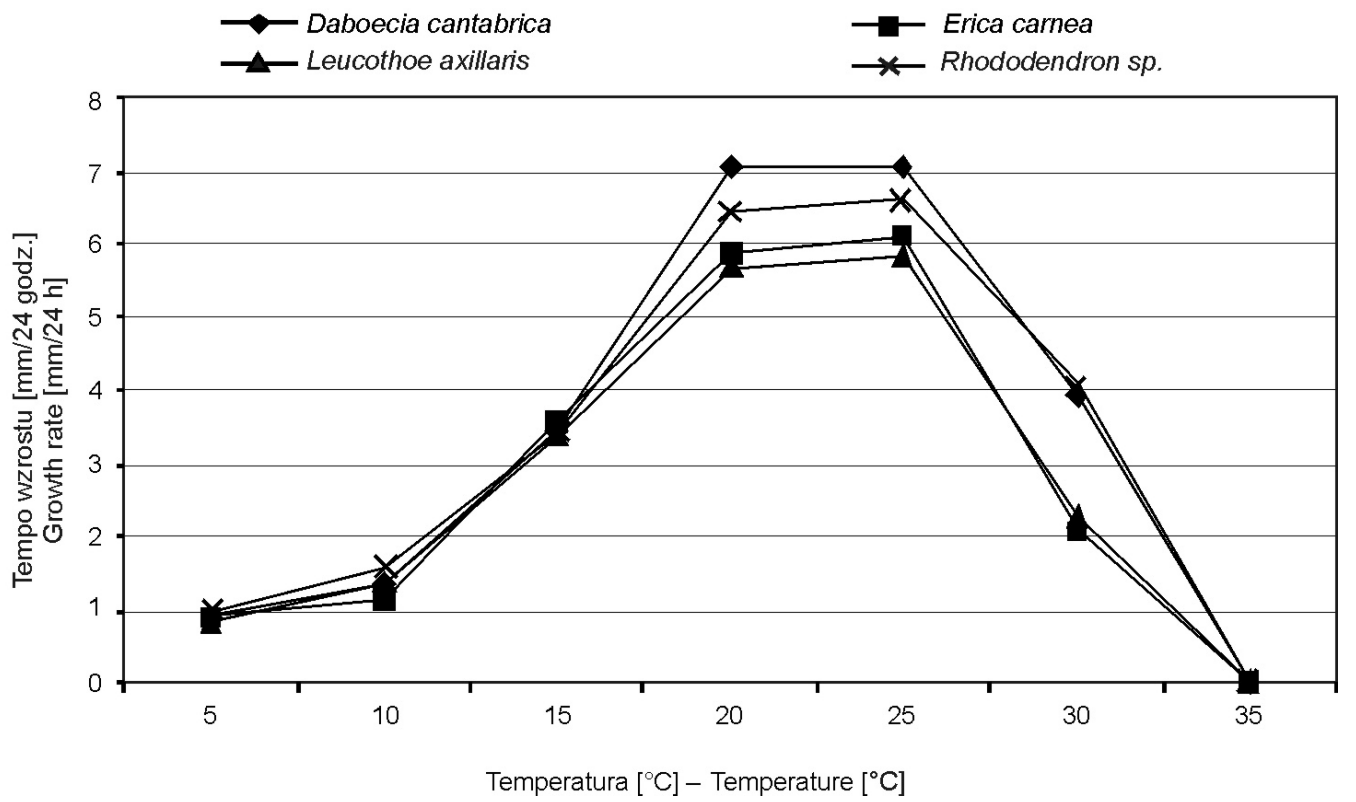

Rys. 2. Tempo wzrostu izolatów $P$. funerea na pożywce PDA w zależności od temperatury

Fig. 2. Growth rate of $P$. funerea on PDA medium in relation to temperature 
W testach temperaturowych badane izolaty $P$. funerea rozwijały się $\mathrm{w}$ temperaturze od 5 do $35^{\circ} \mathrm{C}$. W temperaturze minimalnej, średnie tempo wzrostu dla 4 izolatów wynosiło $0,9 \mathrm{~mm} / 24$ godz. Optimum temperaturowe dla wszystkich izolatów to $20^{\circ} \mathrm{C}(5,7-7,1 \mathrm{~mm} / 24$ godz. $)$ do $25^{\circ} \mathrm{C}(5,9-7,1 \mathrm{~mm} / 24$ godz. $)$. W maksymalnej temperaturze wzrostu $\left(30^{\circ} \mathrm{C}\right)$ izolaty rozwijały się średnio $3,1 \mathrm{~mm} / 24$ godz. Szybszym tempem wzrostu w wysokiej temperaturze charakteryzowały się izolaty $\mathrm{z}$ dabecji i różanecznika. Wzrostu izolatów $P$. funerea nie obserwowano w temperaturze $35^{\circ} \mathrm{C}$ (rys. 2).

Wyniki badań zagranicznych (Madar i wsp. 1991; Gonthier i Nicolotti 2002; Sousa i wsp. 2004; Keith i wsp. 2006; Ozan i wsp. 2012) oraz badania własne wskazują, że zarówno w uprawach, jak i naturalnym środowisku rośnie zagrożenie roślin przez $P$. funerea. Jednakże $\mathrm{z}$ danych prezentowanych przez Vegh (1987) wynika, że wśród ponad 100 chorób opisanych przez niego w szkółkach francuskich, do końca lat 80. XX wieku nie stwierdzono w nich $P$. funerea. Gatunek ten poszerza jednak zakres roślin żywicielskich, począwszy od winorośli, na której został po raz pierwszy opisany, a następnie roślin iglastych i liściastych. Z badań własnych wynika, że w Polsce zasiedla on również rośliny wrzosowate. Aby nie dopuścić do znacznych strat $\mathrm{w}$ uprawach szkółkarskich, głównie poprzez obniżenie ich jakości, istnieje potrzeba rozszerzenia badań, głównie nad częstotliwością jego występowania, szkodliwością i możliwością ograniczenia strat. Wyniki badań nad kolonizacją pędów wrzosów przez ten gatunek świadczą że niektóre izolaty tego grzyba bardzo szybko kolonizowały pędy roślin iglastych powodując ich zamieranie.

Dla producentów roślin iglastych bardzo istotne są źródła $P$. funerea, jak również kontrowersje związane $\mathrm{z}$ jednej strony $\mathrm{z}$ występowaniem tego gatunku na około $10 \%$ żywotników, a z drugiej, z powolną kolonizacją tkanek pędów przez izolat $\mathrm{z}$ tej rośliny. Prowadzone obserwacje w szkółkach wskazuja, że istotnym źródłem patogena są importowane sadzonki i siewki oraz pobieranie sadzonek do ukorzeniania $\mathrm{z}$ zasiedlonych przez patogena nasadzeń. Niewątpliwie bardzo istotne jest obfite nawożenie azotowe prowadzące do wydelikacenia tkanek pędów wierzchołkowych i dające możliwość szybszej ich kolonizacji przez badany czynnik chorobotwórczy. Czynnikiem warunkującym występowanie $P$. funerea jest ochrona szkółek. Jeszcze do niedawna była ona bardzo ograniczona $\mathrm{z}$ uwagi na rzadkie lub sporadyczne występowanie choroby. $\mathrm{W}$ minionych kilku latach wprowadzenie tiofanatu metylowego do programu ochrony żywotnika i innych roślin iglastych spowodowało, z jednej strony, ograniczenie występowania patogena, a $z$ drugiej, przez zbyt częstą jego aplikację z powodu braku innych środków do ochrony, uodpornienie się $P$. funerea na ten związek. Jest prawdopodobne, że powolna kolonizacja pędów żywotnika przez $P$. funerea $\mathrm{z}$ tej rośliny $\mathrm{w}$ doświadczeniu mogła być związana ze znacznie mniejszą aktywnością patogena powodowana przez tiofanat metylu, czego nie stwierdzono używając do inokulacji pędów kultur patogena $\mathrm{z}$ roślin wrzosowatych. Uzyskane dane nad rozwojem omawianego gatunku wskazują, że optymalną dla wzrostu badanych izolatów okazała się temperatura $20-25^{\circ} \mathrm{C}$. Oznacza to, że patogen może się szybko rozwijać od wiosny do jesieni. Z badań hiszpańskich (Santamaria i wsp. 2007) wynika, że dla 8 rodzimych izolatów optimum wzrostu wynosiło $25^{\circ} \mathrm{C}$.

\section{Wnioski / Conclusions}

1. Ocena zagrożenia nasadzeń cyprysika, jałowców, mikrobioty syberyjskiej i żywotnika zachodniego przez $P$. funerea wykazała występowanie tego gatunku na około 0,5 do $9 \%$ roślin $\mathrm{z}$ dominacją na ostatnim z gatunków.

2. Izolaty P. funerea z jałowca i żywotnika kolonizowały fragmenty wierzchołków pędów różnych gatunków i odmian tych roślin. Stwierdzono istotne różnice w tempie kolonizacji pędów poszczególnych gatunków i odmian.

3. Izolaty $P$. funerea $\mathrm{z}$ roślin wrzosowatych $\mathrm{i}$ wody kolonizowały fragmenty pędów wrzosów i 6 gatunków roślin iglastych.

4. Optymalną dla rozwoju P. funerea okazała się temperatura $20-25^{\circ} \mathrm{C}$.

Opracowanie wykonano $\mathrm{w}$ ramach zadania $\mathrm{nr} 1.5$ „Diagnostyka zagrożenia przez agrofagi inwazyjne, podlegające obowiązkowi zwalczania, opracowanie metod zwalczania i zapobiegania ich rozprzestrzenianiu sie", Programu Wieloletniego „Rozwój zrównoważonych metod produkcji ogrodniczej w celu zapewnienia wysokiej jakości biologicznej i odżywczej produktów ogrodniczych oraz zachowania bioróżnorodności środowiska i ochrony jego zasobów, finansowanego przez Ministerstwo Rolnictwa i Rozwoju Wsi.

\section{Literatura / References}

Gonthier P., Nicolotti G. 2002. First report of Pestalotiopsis funerea on Cupressocyparis leylandii in Italy. Plant Dis. 86 (12), p. 1402. Grabowski M., Obere K. 2009. Przyczyna zamierania łusek i pędów żywotnika zachodniego (Thuja occidentalis L.) w terenach zieleni. Zesz. Probl. Post. Nauk Rol. 539: 199-205.

Guba E.F. 1961. Monograph of Monochaetia and Pestalotia. Harvard Univ. Press, Cambridge, Massachusetts, 342 pp. 
Hall G. 1993. An integrated approach to the analysis of variation in Phytophthora nicotianae and redescription of the species. Mycological Res. 97: 559-574.

Keith L.M., Velasquez M.E., Zee F.T. 2006. Identification and characterization of Pestalotiopsis spp. causing scab disease of Guava, Psidium guajava, in Hawai. Plant Dis. 90 (1): 16-23.

Madar Z., Solel Z., Kimchi M. 1991. Pestalotiopsis canker of cypress in Israel. Phytoparasitica 19 (1): 79-81.

Orlikowski L.B., Jarecka A. 2005. Cylindrocladium scoparium w szkółkach roślin iglastych. Sylwan 149 (1): 25-29.

Orlikowski L.B., Ptaszek M., Trzewik A., Orlikowska T., Szkuta G., Meszka B., Skrzypczak Cz. 2012. Zagrożenie upraw ogrodniczych przez gatunki rodzaju Phytophthora. [Risk of horticultural plants by Phytophthora species]. Prog. Plant Prot./Post. Ochr. Roślin 52 (1): $92-100$

Orlikowski L.B., Szkuta G. 2002. Dieback of Pieris japonica caused by Phytophthora citrophthora. Acta Mycol. 36: 251-256.

Ozan S., Kurbetli I., Değirmenci K., Tülek S. 2012. First report of leaf blight of arborvitae (Thuja orientalis) caused by Pestalotiopsis sp. in Turkey. New Dis. Reports (25), p. 14.

Santamaria O., Bajo J., Pajares J.A., Diez J.J. 2007. Susceptibility of Cupressus arizonica and Pinus pinea to Pestalotiopsis funerea isolates. Acta Silv. Lign. Hung., Spec. Edition, p. 283.

Sousa M.F., Tavares R.M., Geros H., Lino-Neto T. 2004. First report of Hakea sericea leaf infection caused by Pestalotiopsis funerea in Portugal. Plant Pathol. 53, p. 535

Vegh I. 1987. Champignons des Arbres et Arbustes d'Ornament. INRA, Paris, 121 pp. 